\title{
CHANGES IN THE ETHNIC STRUCTURE OF BULGARIAN POPULATION BETWEEN THE LAST TWO NATIONAL CENSUSES 2001-2011
}

DOI: http://dx.doi.org/10.18509/GBP.2020.31

UDC: 314.117-054(497.2)"2001/2011"

\author{
Georgy Burdarov \\ Kristina Petrova-Hristova \\ Sofia university "St. Kliment Ohridski”, Sofia, Bulgaria
}

\begin{abstract}
The ethnic structure of the population is an index about ethnic diversity within a country. It is one of the important characteristics of the population because it influences the fertility attitudes, labor activity and the behavior in society. The population in Bulgaria for three decades has been strongly deteriorated - negative rate of natural increase and immigration rate and deteriorated age structure. The ethnicity of the population in the country be composed of three large groups - Bulgarians, Turks and Roma. The data from the last two censuses do not account for much difference in the values presented so far in previous censuses and scientific developments. The higher reproductive attitudes among the Turkish and Roma ethnic groups make impression, compared to the Bulgarian one. It is typically for the traditions in the both ethnic groups. A precondition for stability in the development of the ethnic structure is the so-called preferential ethnic self-consciousness, which is defined in determining the population according to the ethnic group in whose territory they live.
\end{abstract}

Key words: population, ethnic group, ethnic self-consciousness, labor activity, education structure

\section{CHANGES IN THE COUNT AND ETHNIC STRUCTURE OF THE POPULATION OF BULGARIA - HISTORICAL OVERVIEW}

The Balkan Peninsula is a territory inhabited by many ethnic and religious communities. Along with the other characteristics, they are distinguished by different parameters of demographic processes, which lead to irregular changes in the number of persons from the main ethnic groups. This influences the values of their relative shares in the general structure of the population for this purpose.

Bulgaria is no exception in its ethnic composition, the main three groups are Bulgarians, Turks and Roma. The Bulgarian ethnic group has the highest percentage, and traditionally the second and third places are the ones of the Turks and Roma. The Balkans are a place characterized by frequent conflicts, mostly on religious grounds, but the country has established mutual tolerance, which has been aided by the continued cohabitation with different ethnicities in the past.

The census programs almost always included the category of ethnicity, with the exception of the socialist period, during which no ethnic character was present.

The detached censuses mainly used two or three ethnographic features. Thus, the first censuses conducted at the end of the 19th century (1887 and 1892) showed signs of religion and mother language. The census at the end of 1900 also included the sign "nationality". These three indications for characterizing the ethnographic composition of the population were used until 1934 inclusive. 
At the census conducted at the end of 1946, the denomination was dropped and the other two indicators appeared until 1975. At the 1992 census, the observational program included the traits of ethnic group, mother language and denomination.

In order to ensure comparability of the data, the same attributes are included in the 2001 census program as well as the last of 2011. The new point to be highlighted is the voluntary nature of the answers to these three questions concerning unlike all previous censuses when the answers were compulsory.

Population censuses in the country have been conducted since 1881 and one of the conditions for conducting it has been for a period of at least ten years. Due to different political or social problems, the censuses of the population in Bulgaria have not always followed the specified time period. After the onset of democratic change, the trend for a ten-year reporting period has been observed. The last two censuses were conducted in 2001 and 2011, the next one will be conducted in 2021. The 17 national censuses conducted so far give a clear idea of the population in the country during the different historical periods, as well as the structure of its ethnic composition. Fig. 1 shows the reported values.

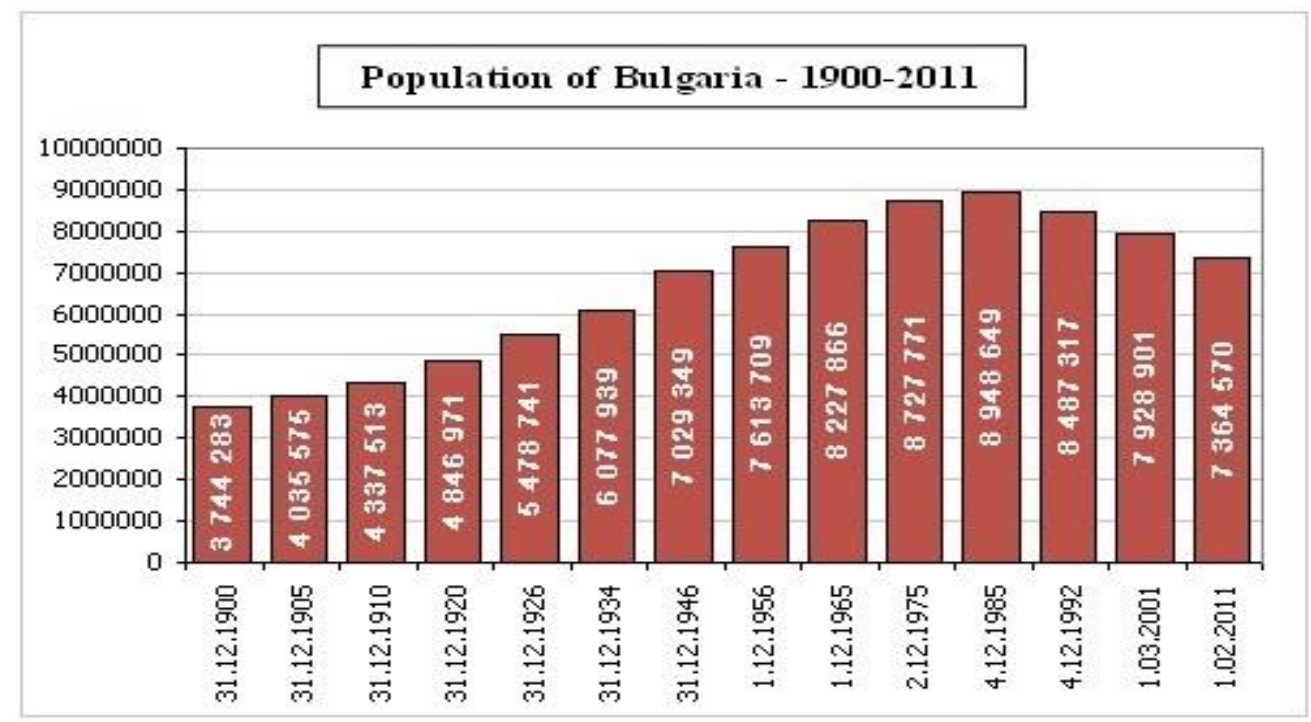

Figure 1. Population of Bulgaria for the period 1900-2011

\section{Source: NSI}

Population data show that there has been a steady increase since the Liberation of the country until 1985. From just over 2 million in 1880, the country's population reached its highest in 1985 of almost 9 million, after which a drastic decline was observed - in 2011 the population was only 7,4 million, down 1,5 million over a 26 -year period and continuing to decline. Such reduction of population for no external reason is not observed in another territory.

The demographic situation is still critical. The population has been declining in recent years. The age dependency ratio continues to increase. As a result of reduced birth rates and increasing mortality, there is a limited reproduction of the population. For the period 2001-2011 the population of the Republic of Bulgaria decreased by 564331 people, the average annual rate of decrease being $0.7 \% .68 .9 \%$ of this decrease is due to the negative natural increase (Atanasova, Naydenov, 2016) [1]

If in economically well-developed countries from Western Europe and North America 
we see natural values of about $0 \%$, evidence of successful demographic transition, in Bulgaria we have values of $-7 \%$ in 1997 and $-6,5 \%$ in 2018 . These values clearly show how deep the demographic problems are and that a working demographic policy is essential to improve the situation. In recent years, much more has been discussed about issues affecting the population, which has led to the prioritization of development axes in this area.

At the first census of the population in the Principality of Bulgaria conducted as of December 31, 1880, only religion and mother language were observed. The ethnic group is also not observed in the next two censuses conducted at the end of 1887 and 1892 . During the unsuccessful census of the population of Eastern Rumelia at the end of 1880 and at its re-holding at the end of 1884 , the nationality was included and significant developments were made on all three indicators. Thus, out of a total of 815951 people living on the territory of Eastern Rumelia in 1880, Bulgarians turn out to be 590 thousand (72,3\%), Turks - 158 thousand (19.,4\%), Roma - 19,5 thousand $(2,4 \%)$., and other nationalities - 48 thousand $(5,9 \%)$. The values were similar to those in the 1884 census were $69,9 \%$ Bulgarians, 20,6\% Turks and 2,8\% Roma.

For the first time in the Principality of Bulgaria nationality was registered at the census in 1900. It is found that 2,9 millions Bulgarians $(77,1 \%), 531$ thousand Turks $(14,2 \%)$, 90 thousand Gypsies $(2,4 \%)$ live in the country and 237,000 Jews, Armenians, Greeks, Russians, Romanians, and more. (6,3\%). (Ilieva, 2012) [2]

Throughout the twentieth century, among the population of the country, of course, with the largest number and relative share is the Bulgarian ethnic community. Traditionally, the second is the Turkish ethnic group, whose values vary across censuses, mainly due to the political regimes in the country. Third is the Roma ethnic group, with a gradual increase. In addition to these three main ethnic groups, there are others in the country, but with significantly less spreading and numbers. These are representatives of the Armenian ethnic group, the Jewish, Wallachian, Karakachan, Russian, Greek, Macedonian, Romanian, Ukrainian, as well as a significant number who have not identified themselves. The Russian and Armenian ethnic groups are the most spread, while the Romanian ethnic group is the smallest.

\section{NATIONAL CENSUS 2001 - RESULTS, CAUSES}

In 2001, the 16th census was conducted in Bulgaria. The results were expected and gave a clear picture of the first decade after the democratic changes. The tendencies are for a continued decrease of the population, and of the three main ethnic groups, it is only in the Roma that we can see a slight increase. Fig. 2 and 3 show the numbers taken into account in the census of the three main ethnic groups.

Compared to the previous census (1992), there is a rather dramatic decline in the total population - almost half a million people in nine years. This was provoked mainly by the political changes that are already opening the borders of the country and the movement of the population is facilitated, therefore it also leads to a stronger immigration flow from Bulgaria to the countries of Western Europe and North America. In addition, we see a decline of about 50,000 and in the Turkish population, which in 1992 amounted to $800,052(9,4 \%)$. This reduction is still echoed by the so-called "big excursion" that led to the forcible eviction of more than 360,000 Turkish citizens in 1989. Since then, the number of the Turkish ethnic group has varied around 8-9\%.

The Roma ethnic group has traditionally registered an increase in numbers compared to the values obtained in 1992, with just over 55 thousand, reaching $4,7 \%$, which is $1 \%$ 
more. It is important to mention that variations in the number in the Roma group are possible, because of the so-called. 'preferential ethnic self-awareness', characterized by self-determination, with respect to the ethnic group in whose territory they live. This is one of the reasons that the data we receive for their numbers is not comprehensive enough.

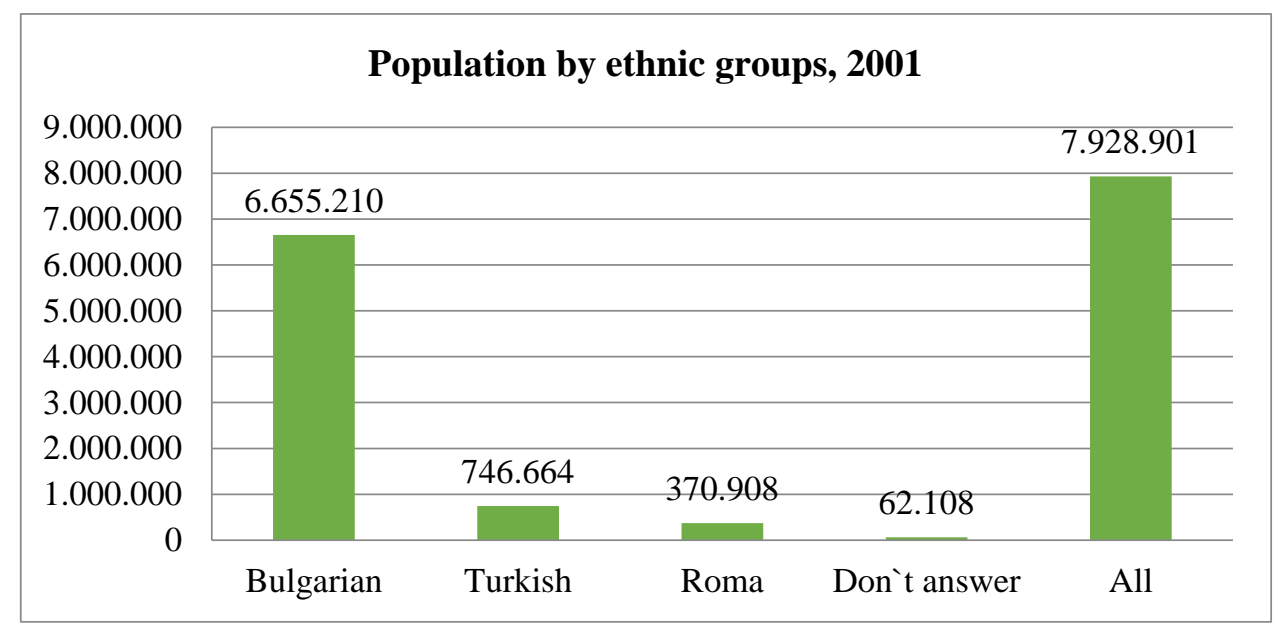

Figure 2. Population in Bulgaria by Ethnic Groups, 2001

Source: NSI

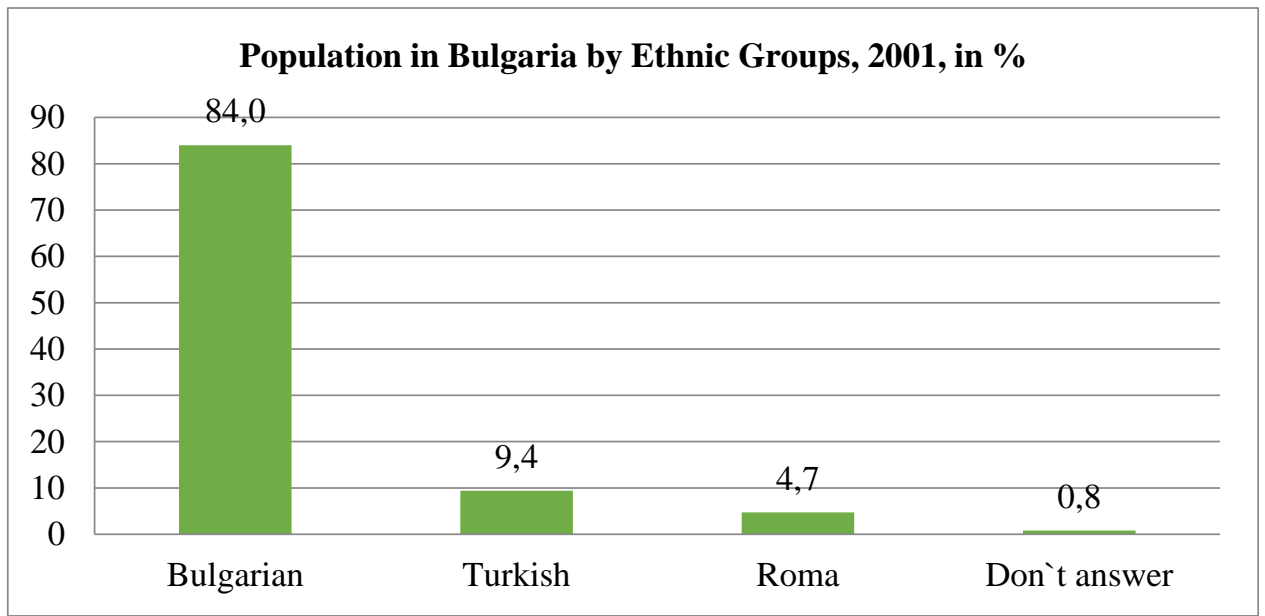

Figure 3. Population in Bulgaria by Ethnic Groups, 2001, in \% Source: NSI

The reasons for the increase among the Roma ethnic group are the tradition of higher birth rates and the badly integration policy.

In fig. 4 depict in relative numbers the number of people from other ethnic groups in the country. The changes in total numbers are insignificant.

In 2011, was conducted the last national census (17th in a row), which collected data on population, housing and other indicators included in the survey. The results are alarming because of the continued decline in population, as well as the complex worsening of demographic indicators (population growth and migrations, high mortality, low birth rate, age structure). An impression is made by another negative trend - the heavily aging population. According to Naydenov and Ivanov (2016) the tendency of population aging leads to changes in its basic age structure - under, in and over working age. Both the aging of the population and the legislative changes in setting retirement ages have an impact on population totals, both under working age. [3] 
This, together with other demographic problems, will in the future create serious problems for the social and pension systems.

The total population decreased by about 550,000 in the ten years between the two censuses. The decrease is due primarily to the high negative population growth, which is $-5.1 \%$ and continues to maintain high values. In addition, about one third of the population decrease is due to external migration (about 30\%).

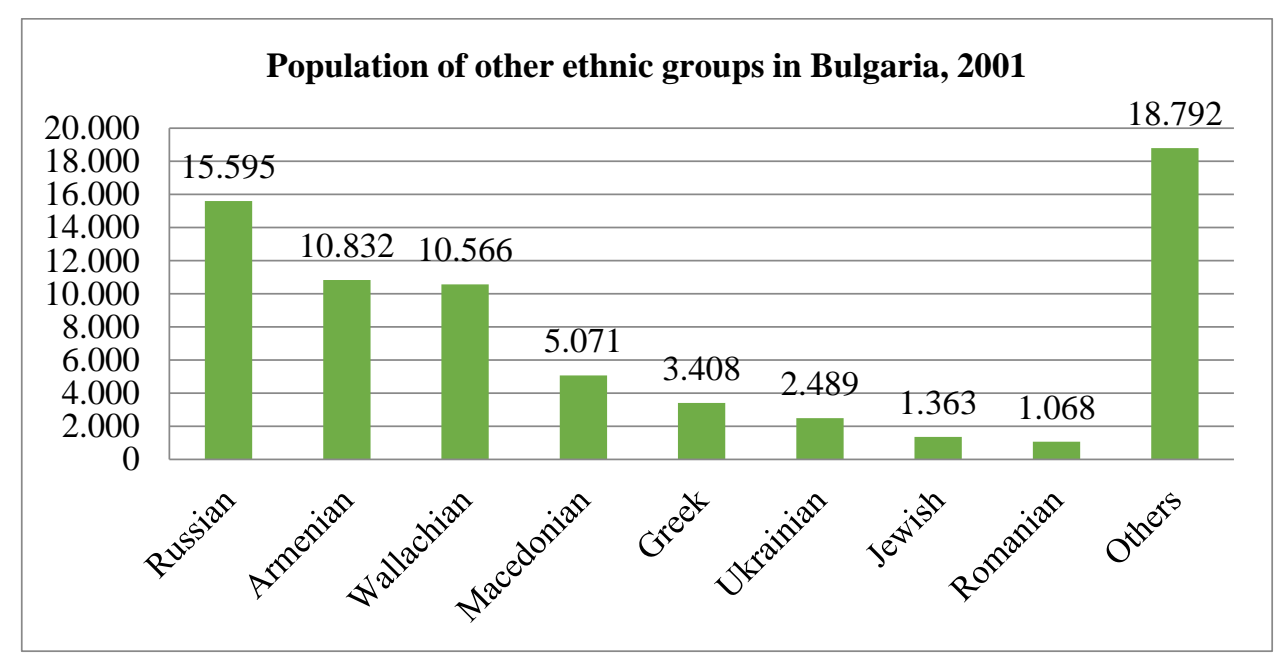

Figure 4. Population in other ethnic groups in Bulgaria, 2001 Source: NSI

The established demographic trends and the increased emigration in the last 20 years affect the number of all ethnic groups in the country.

Again the leading is the Bulgarian ethnic group with $84,8 \%$, the traditional second place is occupied by the Turkish ethnic group with $8,8 \%$, and on the third place is the Roma with $4,9 \%$. In all three groups there were no changes in their characteristic tendencies - a decrease among the Bulgarian ethnic group, relatively equal values among the Turkish and a slight increase among the Roma (figs. 5 and 6).

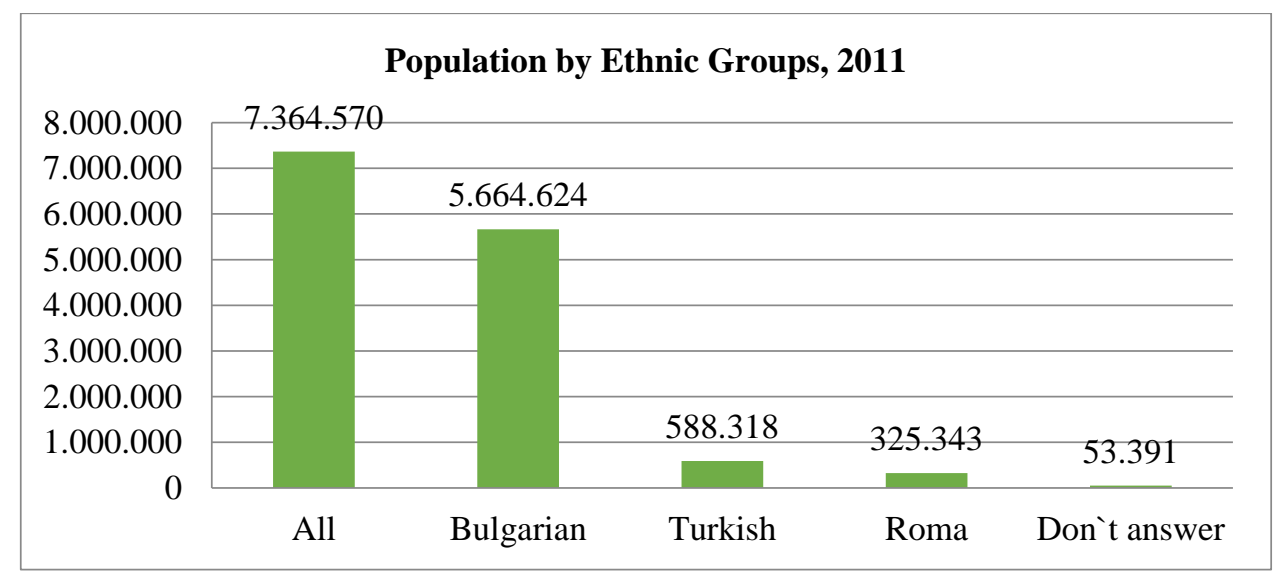

Fig. 5. Population by ethnic groups in Bulgaria, 2011 Source: NSI

The resulting demographic data from the last census confirms general trends, which unfortunately carried a negative sign. Population growth rates continue to maintain high negative levels, and it is clear from the above data that they mostly come from the 
high mortality rate among the population in the country. Although health care is at a much better level, the age structure is in bad condition, resulting in higher mortality.

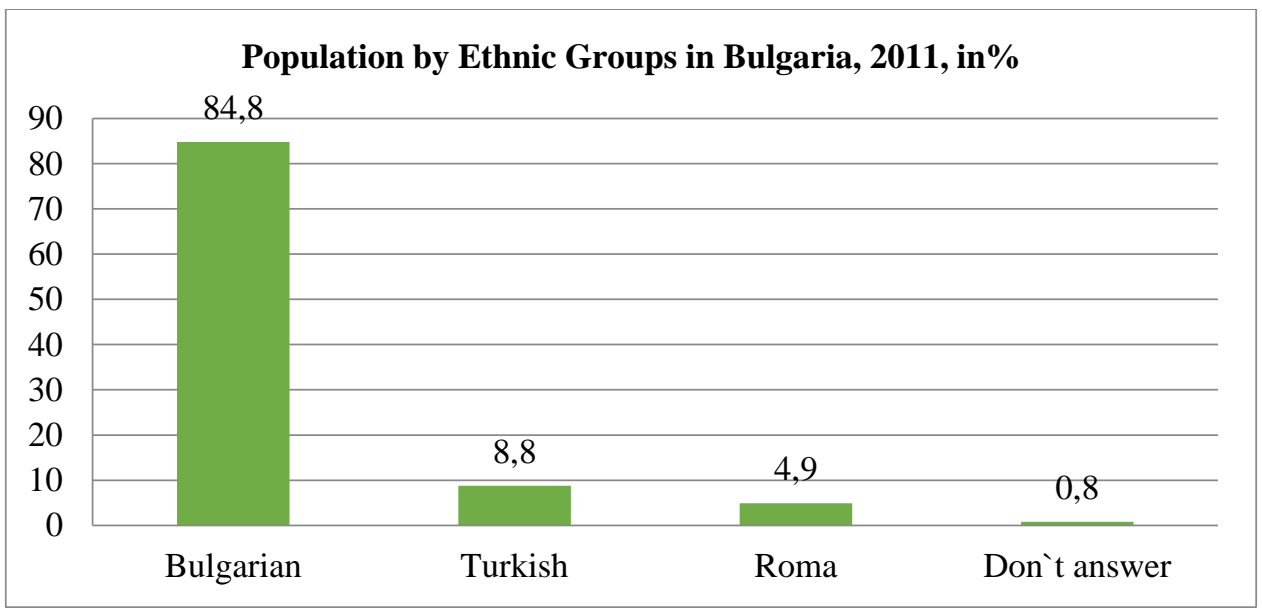

Fig. 6. Population by ethnic groups, 2011, in \%

Source: NSI

Migrations is no exception and also maintains similar values to those of the previous census. The ethnic composition of the population does not undergo drastic changes - the values retain their characteristic trend.

\section{SYNTHESIS OF CHANGES IN ETHNIC STRUCTURE AND THEIR CAUSES. GOOD PRACTICES AND POLICIES}

The changes in the ethnic composition of the population occurring between the two national censuses (2001-2011) are mainly related to the continuing deepening negative trends. We see an overall decrease in the population, of which the Bulgarian ethnic group has the highest percentage. This decrease is mainly due to the high mortality and emigration rates. Our country continues to maintain high mortality rates due to the deteriorating age structure and, consequently, the expanding part of people of overworking age. Attitudes for reproduction among the Bulgarian ethnic group are also lowered, hence the lower birth rate. This, on the one hand, is due to the rising educational level, which marks its highest values so far in the development of the country, and, on the other, to the social insecurity which people in fertile age are exposed.

There is also a decrease in the Turkish ethnic group compared to previous periods. The reasons for the decline among them are mainly related to the easier travel opportunities in Europe after our country's accession to the EU in 2007, as well as emigration to neighboring Turkey. A characteristic feature that helps to maintain slightly higher birth rates than the Bulgarian ethnic group is the religious values and traditions that Muslim religion professes and which people continue to observe.

Considering the results of the last three censuses, it is concluded that the Roma ethnic group is the only one in the country that shows an increase in its number, despite the significant discrepancy between official statistics and scientific and empirical demographic studies, which show even more great increase of the Roma population in the country (Ilieva, 2013). [4]

In addition to the higher birth rate, the Roma ethnic group is also characterized by higher mortality, lower life expectancy, but also lower educational level and economic activity. Due to these indicators it is necessary to implement policies in the field of integration and 
inclusion of ethnicity in the social life in the country. Between the two censuses, Roma integration issues are increasingly discussed. Since Bulgaria's accession to the EU, various programs related to their integration have been developed. Integration programs are also at the national level, which, however, produce the expected results by 2011. According to Burdarov (2013) [5], the most serious problem with the Roma ethnic group is the educational level. The high rate of illiteracy and absolute disparity in this indicator with other ethnic communities in Bulgaria leads to the marginalization of the Roma. With higher education in 2001 were only $0,2 \%$ of the Roma in the country, whereas in 2011 $0,5 \%$. The difference between the other ethnic groups is the most drastic in the secondary education, where for the Bulgarian ethnic group the value is $52,3 \%$, for the Turkish $29,7 \%$, while for the Roma it is only $6,5 \%$ in 2001 and $9 \%$ in 2011 . They have $40,8 \%$ primary education, while $27,9 \%$ initial education. There are no major differences between the two grades in 2001 and 2011. Unfortunately, almost 22\% of the Roma in Bulgaria are illiterate. Perhaps the biggest problem comes from the lack of trained Roma teachers, where Roma children would be able to master the material easily.

Educational problems logically reflect directly on Roma incidence and their standard of living. Only $38,8 \%$ of the Roma are economically active, although in this youngest ethnic group the part of students after the age of 15 and the part of pensioners is the lowest. Only $50,2 \%$ of the economically active population are employed in the Roma, i.e. 19,35\% of all Roma over 15, while three fifths of persons over 15 are economically inactive or $61,2 \%$.

Perhaps the most important factor can be identified for the successful integration of the Roma into raising the educational level and stopping their marginalization in the ghetto. The ghettoes reproduce the model of low education, isolation and discrimination. There is a certain problem in the relations between Bulgarians and Roma. Barriers and stereotypes have been erected on both sides that hinder integration. As Bulgarians discriminate against this ethnic group, so do Roma who are isolated in the ghettos of fear. One closed circle is obtained.

\section{CONCLUSION}

As a conclusion, we can say that the overall picture of the demographic situation in the country is much worse. The data from the last two censuses clearly show a deepening demographic crisis. It is mainly reflected in the sharp decrease in the total population in the country, as well as the deterioration in the age structure. In addition, persistent negative tendencies in terms of population growth rate and migrations are persistent problems - persistently negative values. The established demographic trends and the increased emigration in the last 20 years affect the number of all ethnic groups in the country, as a result of which there have been no significant changes in the ethnic structure of the population in the years between the last two censuses, according to voluntary selfdetermination. The pattern of distribution among the three main ethnic groups is unchanged - leading the group of the Bulgarian ethnic group, followed by the Turkish and Roma. Although the percentages are clearly maintained, the decrease in the Bulgarian ethnic group is in absolute numbers.

According to the Roma ethnic group, as we have noted in the presentation, there is a tendency of increase in their number, which clearly necessitates increased work on the integration of the ethnic group. The positive thing we can emphasize is that at present good results of the measures taken in some regions of the country. 


\section{REFERENCES}

[1] Atanasova, M., Cl. Naydenov Depopulation in Bulgaria and Targeted Investment Programs Bulgarian Experience and Practice, Sat. reports from the scientific conference "Geographic aspects of planning and use of the territory in the conditions of global changes", Varshets, 2016

[2] Ilieva, N. Number of the Roma Ethnic Group in Bulgaria from the Liberation (1878) to the Beginning of the 21st Century According to the Censuses, BAS, Problems of Geography 3-4, pp., 2012

[3] Naydenov, Kl., M. Ivanov Demographic Risk Management in the Republic of Bulgaria Trends and Prospects, Year. of MSU "St. Ivan Rilski", vol. 59, Sv. IV, Humanities and Business Sciences, 2016

[4] Ilieva, N. The Roma in Bulgaria. Number and localization of the Liberation (1878) until the beginning of the 21st century, BAS, S., 2013

[5] Burdarov, G. Current status and positive perspectives on Roma integration in Bulgaria, Friedrich Ebert Foundation S., 2013.

[6] www.nsi.bg 